\title{
Coping Strategies in Families with Intellectual Impaired Children at Dagbreek and Môreson Centres in the Khomas Education Region of Namibia
}

\author{
Aina Simson \\ Ministry of Education, Khomas Education region \\ Andrew Möwes \\ University of Namibia, Windhoek, Namibia
}

\begin{abstract}
Families with intellectually impaired children experience a great deal of stress which demands various internal and external resources for effective coping. This research aimed at investigating coping strategies in families with intellectually impaired children at the Dagbreek and Môreson Centres in the Khomas Education Region of Namibia. For the purpose of this study, a qualitative approach was adopted. Interviews were conducted to collect data with a sample of ten families whose children attended school at the aforementioned centres. The data collected was analyzed using thematic content analysis. The results indicate that parents and guardians received support from partners, siblings, the extended families, social support from others, professional support as well as spiritual support when having an intellectually impaired child. It was further evident from the above findings that parents and guardians are stressed because of the burden of care they carry in raising their children. The researchers recommend that government and non-governmental organizations intervene in order to assist parents and guardians to care for their children.
\end{abstract}

Keywords: intellectual impairment; trauma; coping; Khomas Education Region

\section{INTRODUCTION}

It is estimated that $1-2 \%$ of the world's populations have intellectual disabilities, with higher prevalence rates reported among children in lower income countries (Maulik, Mascarenhas, Mathers, Dua \& Saxena, 2011). Some local experts estimate that approximately 3 percent of the Namibian population experience impairment ((Ministry of Basic Education and Culture, 1999).The presence of an intellectually impaired child shakes the family to its foundations. For these parents, the time of their child's birth may become mixed with stress and despair (Barnett, Clements, Kaplan-Estrin \& Fialka, 2003). These families experience physical and psychological stress which demands various strategies for effective coping.

The ability of families to cope with such situations depends on their internal resources such as faith in God, energy, self-determination and perception of the situation, as well as external resources such as support from family members, relatives, friends, neighbours, professionals, community and government policies and programmes (Morya, Agrawal, Upadhyaya \& Sharma, 2015).

The literature has focused on a variety of stressors and variables considered as mediating some of the effects of stress. One such mediating variable that has received significant attention is that of social support (Jones \& Passey, 2003). Researchers have identified several major elements of social support: financial, emotional, educational, material, formal and informal (Plant \& Sanders, 2007).

According to Seligman and Darling (2007), caring for an intellectually impaired child may directly or indirectly have an economic impact on families over and above its psychosocial costs. This includes both direct costs i.e. expenses for child care, medical care such as therapy, hospital bills as well as medication and special and adaptive equipment. As has been pointed out earlier, financial worries may exist and the family becomes at risk of coping difficulties. In addition, Swenson (2005) agrees that the budget of families with intellectually impaired children may be strained to provide special medical care, transportation or remedial programmes. Owing to greater financial responsibilities, families may find themselves in a situation where they need to cut back on other expenses. 
Venkatesan (2003) reports that the support from spouses, parents, siblings and professionals is an important source of emotional support. Spouses who are unhappily married are likely to suffer stress from the strain in their marriages and one could assume that the strain in their marriages is exacerbated by stress in other areas of their life (Oelofsen \& Richardson, 2006). Turnbull, Turnbull, Erwin and Soodak (2006) noted that a supportive husband, even one who does not participate in child care, seems to be an important predictor of a mother's sense of well-being. It is further noted that having a child with impairment affects not only the parents, but also siblings and relationships among family members. Siblings' actions towards the impaired children are usually connected with parent's reactions towards them. If the parents accepted their child's impairment the siblings will accept it too (Swenson, 2005).

Heller and Caldwell (2006) described two factors associated with successful coping: formal and informal support. Informal sources of support include support from individuals, extended families, grandparents, friends, neighbours, other families with similar issues and groups such as churches. In terms of formal support, there are suggestions that appear helpful: family-centred practice as opposed to child-centred intervention; empowering families; keeping an eye on meso-, exo-, and macrosystem issues; and involving parents in teaching or treatment. Abbeduto, Seltzer, Shattuck, Krauss, Orsmond and Murphy, (2004) have shown that informal support has more positive effects than formal support. Ylven, Bjorck-Akesson and Granlund (2006) maintain that broadly based support systems are composed of friends of all ages, neighbours, co-workers, and others in the community who offer family resources, emotional aid, models of behaviour and sources of information.

According to Cunningham (1996), professional services may be needed to support the family, and to provide the information and skills to enable the informal network to help. It is useful to get as much help as one can from professionals and other service providers, which at times turn out to be difficult (Glidden, Billings \& Jobe, 2006). The extent and type of needs may differ widely from one family to the other within the life cycle of the same family. Such needs may range from needs for information, counselling or advice, to needs for specifics services (Gupta \& Singhal, 2004).

There is need for people from outside to intervene in assisting families to reach their goals in bringing up their children (Bauman, 2004). Stonemann and Gadvidia-Payne (2006) concurred by stating that outsiders' assistance, e.g. financial support, taking children for a walk and transport services greatly assists those families with intellectually impaired children to maintain a normal life. In addition, Ylven et. al. (2006) report that families without socially supportive networks are likely to suffer from a wide range of negative physical and psychological health consequences such as depression.

Another variable considered as important in mediating the effects of stress is that of spiritual support. Spirituality can be described in various ways: faith in humanity, ethical behaviour, concern for others or interaction in relation to a greater Being (Gupta \& Singhal, 2004).

Gupta and Singhal observed that many people find spiritual support in the form of prayer, literature, participation in religious activities, joining organisations or attending religious services invaluable in terms of alleviating stress. Neely-Barnes and Dia (2008) showed that faith and religious coping methods are the most frequently reported coping strategies among families with intellectually impaired children. Thus, religion offers guidelines for living and offers a sense of stability. The question has been raised as to whether more people use religion as a coping strategy compared to other types of strategies, and whether more people turn to religion in times of crisis than at other times of their lives. It was found that individuals appear to involve themselves with religion to a greater extent in more stressful situations than in less stressful moments of their life (Bauman, 2004). McCubbin and Patterson (1983a) explained how spiritual support played an important role in the families' ability to manage stress, particularly in the most severe situations. Poston and Turnbull (2004) broke down religious coping strategies in order to determine which type of religious coping is helpful or harmful. Spiritual support, prayer and benevolent religious reframing were found to be helpful, whereas congregational support were found to be harmful (Poston \&Turnbull, 2004).

The literature on coping strategies revealed that the ability of family members to cope with an intellectual impaired child depends on both internal and external resources. There is hardly any study on the issue of how families with intellectually impaired children cope in Namibia. The purpose of this article is to provide information on this subject by presenting the results of a qualitative study on families coping in two selected centres in the Windhoek region of Namibia. 


\section{METHOD}

\subsection{Research Design}

A qualitative approach was employed to gain insights into coping strategies used by families with intellectually impaired children at Dagbreek and Môreson Centres in the Khomas Education Region of Namibia. Qualitative methods attach significance to individuals' subjective experience and how they understand events in their lives (Gay, Mills \& Airasian, 2009). This design was suitable for the study as the researchers aimed at gaining understanding of what coping strategies families with intellectual impaired children use. In addition, a qualitative method allowed the researchers to examine the experiences of the parents/ guardians as revealed by their oral responses.

\subsection{Population}

The population of the study consisted of families of intellectually impaired children at Dagbreek and Môreson Centres in Windhoek in the Khomas Education Region of Namibia. There were one hundred and ten (110) families with children at the Dagbreek Centre while there were one hundred and twenty (120) families at Môreson Centre at the time when the study was conducted.

\subsection{Sample}

Purposive sampling was used to collect the sample. There are different types of purposive samples. The critical case sampling method was utilized for this study. It has to be noted that critical-case sampling involves selecting cases that are believed to be particularly important for the study at hand (Johnson \& Christensen, 2008). Critical-case sampling was done so that the samples represent the above mentioned population and are unbiased. Samples were drawn from moderate to severe cases of each of the following conditions associated with intellectual impairments, namely: Down's syndrome, Autism, Epilepsy, Trauma and Foetal Alcohol Syndrome as per the comprehensive list provided by these centres. Children of the participants ranged from ten to sixteen years in age. The researcher chose 10 families who had a child with one of these listed impairments as participants for the study. The samples included five families at each of the centres.

\subsection{Research Instruments}

Interviews were administered to collect data. Interviews are aimed at exploring participants' experience, feelings and views about intellectually impaired children (Johnson \& Christensen, 2008). There are different types of interview methods that can be used to collect qualitative data. The researcher used standardized open-ended interviews to get views and opinions on the phenomenon to be studied. The standardized open-ended interview was used because the method allows all respondents to answer the same questions, thereby guaranteeing comparability and consistency of interviewees' experiences. Another reason was that the standardized open-ended interview reduces interviewer effects and bias when several interviewees are involved (Gay et al., 2009). During the interview session, the researcher tape-recorded the data that were then transcribed, and later assisted in the analysis and data presentation.

\subsection{Procedure}

A letter requesting permission, outlining the purpose of the study and its significance was sent to the Permanent Secretary of the Ministry of Education, Director of Education and principals of the selected centres. After identification of potential participants at the two centres, participants were contacted telephonically and informed about the purpose of the study. After consent was obtained from the participants, interviews were conducted with parents/ guardians who had intellectually impaired children in their families/households. For comfort and convenience, participants were interviewed at their homes. The researcher used an audio-recorder to collect all data.

\subsection{Data Analysis}

Content analysis was used to capture meaning from the data collected. Interviews from participants support and clarify qualitative data analysis. The responses from parents and guardians relating to their experiences of having a child with intellectual impairment were placed into themes, sub-themes and categories created by the researcher and guided by the data obtained. The data collection was undertaken through individual interviews, one participant at a time. The audio tapes were transcribed verbatim and participants were assigned pseudonyms in order to respect anonymity. The transcripts 
were then analyzed using the content analysis method to identify the theme and sub-themes arising from the data. In accordance with the core theme, coping strategies, the following six sub-themes were then identified: support from partners and siblings; support from extended family; social support from others; professional support; spiritual support and internal/personal strategies that emerged from the subsequent creation of categories and coding of the transcript data. The content analysis method is a method of data analysis where a researcher is central to the analysis of information gained (Gorman \& Clayton, 2005). Participants' verbatim quotes were used as lowinference descriptions to support the sub-themes and categories identified.

\section{RESUlts AND DisCuSSION}

In this section the researchers presented the research findings according the research sub-themes and categories, in each case providing narrative examples. Table 1 presents the findings in the study. It illustrates five sub-themes as well as their sub-categories all aimed to answer the main research question of what coping strategies families with intellectual impairment use. The following subthemes were noted: support from partners and siblings; support from extended family; social support from others; professional support and spiritual support.

Table1. Presentation of Main Themes and Sub-themes

\begin{tabular}{|l|l|l|}
\hline Theme & Sub-themes from & Categories \\
\hline $\begin{array}{l}\text { Coping } \\
\text { strategies }\end{array}$ & $\begin{array}{l}\text { Support fouple commitment and support; support from the father (single } \\
\text { partners and siblings }\end{array}$ & $\begin{array}{l}\text { Cupport from } \\
\text { mother); siblings with daily care and mother supplements income. }\end{array}$ \\
\hline & $\begin{array}{l}\text { family support from extended family members (care giving) and } \\
\text { financial support from extended family }\end{array}$ \\
\hline others & Professional support & $\begin{array}{l}\text { Support from social network (mothers group, church members, } \\
\text { community); social support from friends; financial support from } \\
\text { friends; support from institution (hostel, medical aid) and support } \\
\text { from neighbours (social contact) and seeking financial assistance } \\
\text { from employer }\end{array}$ \\
\hline Professional support (doctors, psychologists, therapists). \\
\hline & $\begin{array}{l}\text { Spiritual support - strengthened through belief; spiritual support } \\
\text { through targeted church interventions; spiritual support- general } \\
\text { (attend church services), motivational talks from spiritual leaders; } \\
\text { spiritual support for child through friends; financial support from } \\
\text { church groups and material support from pastor. }\end{array}$ \\
\hline
\end{tabular}

\subsection{Sub-Theme One: Support from Partners and Siblings towards Intellectually Impaired Children}

The categories identified under this sub-theme were: couple commitment and support; support from the father (single mother); siblings with daily care; and mother supplements income.

\subsubsection{Couple Commitment and Support/Support from Father (Single Mother) and Siblings with Daily Care}

The first, second and third coping strategy had the same value of $29 \%$ by less than one third of the parents and guardians. The first was that of couple commitment and support towards intellectually impaired children. A parent (father) said: "We do not need extra support because my wife and I support each other." The second was that of support from the father (as described by a single mother). Another parent (mother) said: “His father takes him to school, Dagbreek Centre. 'The third was that of support by siblings with the daily care.

Yet another parent (mother) said: 'I take care of her as well as receiving assistance from siblings". The findings portray the findings by Turnbull et al. (2006) when they mentioned that a supportive husband, even one who does not participate in child care seems to be an important predictor of a mother's sense of well-being. This perspective was given further weight by Swenson (2005), when he reported that the ability of normal siblings to adapt to having a sibling with intellectual impairment in the family seemed to be closely related to how well the family accepts the problem.

The first coping strategy was couple commitment and support towards intellectually impaired children. The fact that spouses supported each other and shared tasks of looking after the impaired child is of great importance, as it increases family cohesion and feelings of togetherness. Such a coping strategy is very helpful in the face of stress caused by the impaired child. It appears that the 
parents' ability to work together to meet the challenges presented by the child strengthened their own well-being and quality of the care they provided for the child. Moreover, it increased their selfconfidence because they could feel that they can manage the demands of caring for the child. In this way more independence and self-sufficiency were gained.

Overall, support from spouses seemed to have the effect of making parents accept their child, maintaining high commitment, strengthening and motivating them, thus experiencing a sense of relief from the challenges of caring for their impaired child.

The second strategy was support from the father (as described by a single mother). Apparently the support rendered by the father displays an optimistic attitude towards the challenges of care of the impaired child. Indeed, the father went through this difficult situation with some sense of courage and commitment. This means that child care was shared and hence reflects openness; such a situation improves the quality of both family life and the well-being of the impaired child. It must be pointed out that sending the child to Dagbreek Centre offered the family a resting period. The indication is that the parents appeared to have trusted that the child was in good hands at the centre and hence, they could have some relief.

On the whole, it seems that the input by the father enabled the family to speak openly with one another concerning the challenges of care, enabling them to cope well.

The third strategy was assistance from siblings with the daily care of the impaired child. The deduction here is that the existence of the impaired child may be beneficial to the other siblings. The effect on the siblings who assisted in the care could be pride and satisfaction at being capable of taking care of their impaired siblings. Perhaps the co-operation in the tasks of care displayed by siblings was an emulation of the positive attitude reflected by parents. Overall, the support rendered by siblings could result in the development of a great sense of sympathetic behaviour. Thus, the input from siblings remains a valuable contribution in alleviating the challenges faced by parents and guardians of impaired children.

\subsubsection{Mother Supplements Income}

The fourth strategy was that of the need of the mother to supplement income, which was expressed by more than a tenth (14\%) of the parents and guardians. A parent (mother) indicated: "it is not easy because when she got sick, she has to visit the doctor immediately. Her medications are quite expensive and I have to struggle for the fund."'. The finding correlates with findings by Seligman and Darling (2007) who reported that caring for an intellectually impaired child may directly or indirectly impose economic burdens on families in addition to their psychosocial costs. This impact includes medical care: therapy, hospital bills as well as medication and special equipment. This was further supported by Swenson (2005) who agreed that the budget of families with intellectually impaired children may be strained to provide special medical care, transportation or remedial programmes.

Clearly, the challenge here is limited financial resources, particularly for a single mother. This could, therefore, mean that parents have problems in finding funds for the care of their impaired children. It implies that parents might be at a loss because of failure to meet the financial needs of their children. This causes worry, insecurity and helplessness on the part of the mother.

Such a situation makes caring for the impaired child difficult and could make the parent develop feelings of sorrow. However, generally, parents tended to develop a sense of resilience and strength in meeting the challenges of care. In respect of these findings, it is suggested that active support by social welfare organizations could improve the plight of families with impaired children.

\subsection{Sub-Theme Two: Support from Extended Family towards Intellectually Impaired Children}

The categories identified were: family support from extended family members (care giving) and financial support from extended family.

\subsubsection{Family Support from Extended Family Members (Care Giving)}

The first was that of family support from extended family members (care giving) reported by a high percentage $(83 \%)$ of parents and guardians. The following excerpt could best illustrate the view of one parent (mother):

'I must say I am lucky because my relatives are very supportive towards my son's condition. Each one of them is bringing his or her side to help. It became a routine to us all in the family." 
These findings are in agreement with those of Heller and Caldwell (2006), who described informal sources of support from extended families, friends, neighbours, other families with similar issues and groups such as churches. This was further stressed by Abbeduto et al. (2004) when they stated that informal support had more positive effects than formal support.

The message communicated here is that support from extended families is essential for managing the care of the impaired child. It implies that, being close, the extended family refers to people who can help in the care of the child. Such help offered parents a rest and enables them to attend to other social functions. It appears that the effectiveness of the support from the extended family assisted parents and guardians to cope with the demands of care for their children. This support allowed them to feel as if others accepted their family as they are.

Accordingly, it is clear that this support from the extended family is important in making them further accept their children's impairment, as they do not feel neglected. Although families with impaired children seem to manage their families, the additional support provided by the extended family enables them to effectively cope with challenges of care.

\subsubsection{Financial Support from Extended Family}

The second was that of financial support from the extended family reported by nearly one fifth (17\%) of the parents and guardians.

A parent (father) said: "I look for funds from extended family members to cater for her needs like toiletries. I try to make her look presentable just like my other children." There is overwhelming support for this in Stonemann and Gadvidia-Payne (2006) who maintained that the help given by outsiders such as giving money, taking children for a walk and transport services greatly assists the families with intellectually impaired children to maintain a normal life.

Clearly, financial resources appear to be the most important single factor in assisting parents and guardians to cope with the care of their impaired children. This kind of support came as a relief to parents and guardians who found it very helpful. In addition this support seemed to reduce the negative challenges faced by these families in their day-to-day care of their children. Overall, the assistance rendered by extended families gave hope and confidence to parents and guardians of the impaired children.

It can therefore, be concluded that families of intellectually impaired children receive support from other family members that enables them to cope with their child's situation. Therefore, it is suggested that government should increase a social grant for impaired children with a view to alleviate the challenges they face.

\subsection{Sub-Theme Three: Social Support from others towards Intellectually Impaired Children}

The categories identified were: support from social network (mothers' group; church members; community,) social support from friends, financial support from friends, support from institutions (hostel, medical aid) and support from neighbours (social contact) and seek financial assistance from employer.

\subsubsection{Support from Social Network (Mothers' Group; Church Members)}

The first strategy was that of support from social networks (mothers' group; church members; community) reported by one third (33\%) of parents and guardians. This was reflected in a statement by one parent (mother) who said: "I used to attend workshops to acquire information and knowledge on how to take care of my son since his father was not supportive. Sometimes I go to Onyose Trust where a group of mothers with intellectually impaired children gather to share ideas and support as well as to encourage one another."

This finding mirrors findings by Ylven et al. (2006) who reported that support systems composed of friends of all ages, neighbours and others in the community offer resources to the family, emotional support, and a model of behaviour and sources of information.

Naturally, individuals look around for support systems when they are confronted with problems. Therefore, most parents and guardians appreciate the support from the social network since it proves helpful to them, as it makes the challenge of care more tolerable. 
However, the support given by the social network could make them experience feelings of inadequacy to manage their children. Whatever the situation, the interaction could make them understand the impairment of their children. Support groups should be promoted to enable the family network to improve their understanding of impaired children, hence, making parents and guardians cope well.

\subsubsection{Social and Financial Support from Friends, and Support from Institutions (Hostel and Medical Aid)}

The second, third and fourth coping strategies had the same value of about one fifth (17\%) of parents and guardians. The second strategy was that of social support from friends. Another parent (mother) said: "my friend Paula is always coming forward with help, she makes my life easier." The third strategy was that of financial support from friends. One parent (father) said: "although I take her to school every day, this drains us a lot. Sometimes we have to borrow money from our friends for fuel." The fourth strategy was that of support from institutions such as hostel and medical aid. A parent (mother) said: "He is a hostel boarder and so things are a bit lighter in terms of transport cost."

These findings are once more consistent with those reported by Stonemann and Gadvidia-Payne (2006) who stated that the help given by outsiders such as giving money, taking children for a walk and transport services greatly assists the families with intellectually impaired children to maintain a normal life.

If we look at more details regarding second strategy of social support, it can be deduced that support from friends allowed parents to develop a feeling of confidence in caring for their children. This implied acceptance of the impaired child, thus making the process of care giving easier. In addition, the interaction between parents and friends offered much needed encouragement and strength. Indeed, the care for an impaired child requires a great deal of courage and commitment. All things considered, it appears that the acceptance of friends provided for the integration of the impaired child into society, though to a limited extent. It is suggested that such a positive contribution to the welfare of the impaired children should be maintained and improved by all means possible.

The third coping strategy mentioned above was that of financial support from friends. The message communicated here is that friends showed concern for the impaired child by providing financial resources and this increased feelings of togetherness among friends and the parents.

This implies that the family's ability to cope was strengthened. Furthermore, the financial support given by friends was of great importance for the overall family well-being and cohesion.

It is suggested that support groups that include friends should be promoted to enable them to continue providing financial assistance, in order to enable parents and guardians to support their children.

The fourth coping strategy consisted of support from institutions such as hostel and medical aid. Clearly, this help was very important as it provided some form of respite to parents. It implied lessening their burden of care, at least for a certain period, while the child was in the hostel. However, the efficacy of such support depends on the availability of certain facilities in institutions. It is suggested that the government should disseminate information regarding the availability of hostels and ways of accessing help at such institutions in order to assist parents and guardians to care for their children.

\subsubsection{Support from Neighbours (Social Contact)}

The fifth and sixth strategies also carried the same value of $8 \%$ and was reported by very few parents and guardians. The fifth strategy was support from neighbours (social contact). A parent (mother) said: "My neighbours are good people, because if they do not see us for two days or so they always come to ask us if everything is fine now that they did not see us for the past two days." It appears that, being close, the support given by neighbours has far-reaching positive effects on the welfare of the impaired child. This implies building confidence in such families, hence enabling them to cope well. The heartening finding is that neighbours were described as 'good' which indicates that parents and guardians trust and value their assistance.

Indeed, it reflects a feeling of satisfaction which helps them to manage their families. It is believed that good neighbours are friends in need and friends indeed; as such they should continue to support the impaired children. 


\subsubsection{Seek Financial Assistance from Employer}

The sixth strategy was to seek financial assistance from the employer. Another parent (mother) said: "When things get tough, my employer assists me financially". This finding is consistent with the findings by Bauman (2004) who suggests the need for people from outside to intervene in assisting families to reach their goals in raising their children .The deduction here is that financial assistance lessened the challenge of care faced by parents and guardians which enabled them to cope with their responsibilities in terms of their children's impairment. In fact, parents and guardians found this kind of support invaluable. The retention of staff at work places required employers to attend to staff problems, which in turn enabled them to manage the challenge of care giving of their children. It is suggested that such a healthy relationship between employers and employees should prevail to assist parents and guardians in the process of giving care to their children.

\subsection{Sub-Theme Four: Professional Support towards Intellectually Impaired Children}

The category that emerged focused on: professional support from doctors, psychologists, therapists. Thirty percent (30\%) of parents and guardians pointed out that they received professional support and assistance from doctors, psychologists, therapists. On the other hand, $70 \%$ were silent about seeking professional assistance. The first three strategies had the same value of $10 \%$ expressed by one tenth of parents and guardians.

The findings suggested four strategies regarding professionals support used by parents and guardians in the care of their impaired children. These include: support from doctors, psychologists, therapists and silence about seeking general professional assistance. The four strategies that emerged from the findings of this study need to be investigated further.

\subsubsection{Professional Support from Doctors}

The first was that of professional support from doctors. A parent (mother) said: "I had to take him to the doctor almost every two weeks."

The message communicated here was that parents and guardians closely and frequently interacted with doctors largely owing to the condition of their children. It implies that they had hope that scientific information could offer a solution to their problem. It is not clear though, whether medical professionals displayed empathy and sympathy when dealing with impaired children.

Care and commitment of doctors help to ease the challenges of care, thus can be regarded as a cure in itself. Although the process to find professionals might have been difficult, parents and guardians persevered until appropriate help was rendered by health service providers. It is suggested that no matter how difficult parenting an impaired child could be, parents and guardians should demonstrate an attitude of fortitude while working work with professionals.

\subsubsection{Professional Support from Psychologists and Therapists}

The second was that of professional support from psychologists. Ayne (mother) said: "He does not do well in school and this was a disappointment so the school referred us to a psychologist Dr Fourie." The third was that of professional support from therapists. Another parent (grandmother) said: "Now that I adopted her, I put her on my medical aid which helps me to pay her medication and take her to a therapist."

There is overwhelming support for this professional assistance in Glidden (2006), who reported that it is useful to get as much help as one can from professionals and other service providers. However, accessing such help tends to be difficult at times. Cunningham (1996) concurred that professional services may be needed to support the family and provide the information and skills to enable the informal network to help.

It is evident that no matter how difficult dealing with professionals could be, parents and guardians persevered as they sought a solution to their children's condition. The indication is that they hoped and trusted that the support from professionals could assist them in the care of their children. However, it is possible that they could not see the service providers as mostly needed by the condition of their children. In such cases, they could provide care in the way they considered most appropriate. It seems that dealing with professionals was one of the most helpful coping strategies at the disposal of parents and guardians, but it remains imperative that they exercise patience when dealing with medical professionals. 
The third strategy was to seek professional support from therapists. It appears that dealing with therapists also happens to be a process which requires patience as the interaction undertakes the challenges step by step.

Indeed, the process is characterised by long analyses and reviews. Moreover, it must be pointed out that although some parents and guardians may want quick solutions to their problems, health providers operate on standard principles and procedures, consequently there could be delays. It is likely that the manner in which professional interacted with parents could have influenced acceptance of their children. Accordingly, it is suggested that more parents and guardians should seek assistance from medical professionals as it helps them to manage well in the care giving process of intellectually impaired children.

\subsubsection{Silence about Seeking Assistance from Professionals}

The fourth strategy was occupied by silence about seeking assistance from professionals by a high percentage $(70 \%)$ of parents and guardians. The deduction here is that although they were silent, it does not necessarily imply that they did not seek professional assistance. It could mean that their energy was directed to the care of their children. Some parents and guardians do not feel comfortable in seeking outside help; instead they are pre-occupied with the caring business.

It is suggested that advocacy groups should raise awareness on the need to obtain assistance from individuals and organizations.

\subsection{Sub-Theme Five: Spiritual Support towards Intellectually Impaired Children}

The main categories identified were: Spiritual support - strengthened through belief; spiritual support through targeted church interventions; spiritual support- general (attend church services); motivational talks from spiritual leaders; spiritual support for child through friends; financial support from church groups and material support from pastor.

In terms of spiritual support $23 \%$ indicated that they received spiritual support through targeted church interventions, while $15 \%$ indicated that spiritual support through church service assisted them in the care of their children. An equal percentage (8\%) of parents and guardians mentioned support in each of the following four categories: motivational talks by spiritual leaders, spiritual support for children from friends, financial support from church groups and material support from a pastor greatly assisted them in coping with the challenges of raising these children.

The findings suggested seven coping strategies regarding spiritual support used by parents and guardians in the care of their impaired children. These were: spiritual support - strength coming through belief; spiritual support through targeted church interventions; spiritual support- general (attending church service); motivational talks from spiritual leaders; spiritual support for child through friends; financial support from church groups and material support from a pastor. The seven strategies that emerged from the findings of this study need to be explored further.

\subsubsection{Spiritual Support - Strengthened through Belief}

Thirty percent of parents and guardians confirmed that spiritual support strengthened through belief greatly assisted them to care for their children. One parent (father) said: "I only listen to the gospel radio programmes mostly on Sundays, just to comfort myself. After listening to this, I feel good just as if I was in church or at a gathering where we have people of the same problem as mine (of having an impaired child). " In the same vein, Neely-Barnes et al. (2008) showed that faith and religious coping methods are the most frequently reported coping strategies among families with intellectually impaired children. Therefore, religion offers guidelines for living and offers a sense of stability.

It is evident therefore, that parents and guardians used spiritual support to alleviate challenges associated with the impairment of their children. It appears that the belief in a certain religion may explain events such as the occurrence of intellectual impairment. Hence, parents tended to accept their impaired child as something which is God-given, and thus often showed acceptance of the situation. Perhaps, the patience and passion they displayed could have been based on the belief that they will be rewarded by God in one way or another. Thus, belief in God was a source of comfort for them and helpful in creating a positive perception of their impaired child. Since people find hope in religion, it is suggested that parents and guardians could be more involved in religious activities, e.g. groups where information on how to manage their children can be shared. 


\subsubsection{Spiritual Support through Targeted Church Interventions}

The second strategy was that of spiritual support through targeted church interventions expressed by about one quarter (23\%) of parents and guardians. Another parent (father) said: "We attend church services as well as workshops prepared by church members just to encourage parents and families with intellectually impaired children. It really assisted us so much, by learning that you are not the only one in such a problem. 'This finding was supported by McCubbin and Patterson (1983a) when they reported that spiritual support played an important role in the family's ability to manage stress, particularly in the most severe situations, such as dealing with intellectually impaired children.

The findings indicated a number of influences strategies, e.g. providing teaching and a framework for families with impaired children to view their situation more positively. This offered a way for parents to interpret their child's impairment in a positive way.

Furthermore, encounters in church gatherings convened specifically for discussing the challenges of care for impaired children made the parents more approachable and willing to accept their situation.

In addition, the effects of the workshop may make parents and guardians realise that their problems are less challenging than those of others. This in turn serves as encouragement to execute their duties.

Accordingly, targeted church interventions greatly assisted them to care for their children. Therefore, it is suggested that awareness campaigns should be undertaken in order to make the community understand challenges amongst families with impaired children.

\subsubsection{Spiritual Support in General through Attending Church Services}

The third strategy was that of finding spiritual support in general through attending church services noted by over one tenth (15\%) of parents and guardians. A parent (mother) said: "I go to church where we receive a lot of information and support." Again this finding is connected to those of McCubbin and Patterson (1983a) when they explained how spiritual support played an important role in the family's ability to manage stress, particularly in the most severe situations.

It is clear that spiritual beliefs and a sense of purpose in life enabled parents and guardians to accept their child's condition in a positive way. Perhaps their faith had led them to believe that they had been specially selected to provide comfort and care to their children. Their regular attendance at church services made them perceive their impaired children as part of them, thus their belief helped them to be calm and relaxed.

It must be pointed out that the effect of such acceptance of the impaired child could have increased their spirituality. As parents and guardians used spiritual support to cope with the care of their children, it is suggested that they should arrange regular (mid-week) outreach sessions.

\subsubsection{Motivational Talks from Spiritual Leaders}

The fourth strategy was attending motivational talks from spiritual leaders. One parent (father) said: "we attend workshops prepared by church members just to encourage parents and families with intellectually impaired children."

These findings suggest that general church services may not be enough for providing coping strategies for parents and guardians with impaired children. It appears that for them to become effective in their parenting services they need assistance in order to have a greater sense of control over their children, hence the need for motivational talks from spiritual leaders. Furthermore, their beliefs seem to have provided a coping resource for the challenge of caring for their impaired children, i.e. giving hope and resilience.

In considering the above findings, it is suggested that other approaches and coping strategies should be taught to parents with impaired children.

\subsubsection{Spiritual Support to the Child from Friends}

The fifth strategy was the giving of spiritual support to the child from friends. One parent (mother) explained: "the same friend is the one coming to visit us and when my son is around she always invites him to church. The day I am not going to church she always takes him with." This finding suggested that most parents and guardians valued assistance from their friends as a form of spiritual support for the care of their children. It implies that they viewed this kind of support as very helpful and thus they appreciated it. In addition, the will to support requires a great deal of religious 
commitment and sacrifice. For this reason, spiritual support rendered by friends to help parents and guardians care for their children was appreciated. Perhaps, what made them to gladly accept it was the fact that it came from close friends.

This way, the parents felt strengthened in their duty of care. It is suggested that support from more sources be obtained in order to assist the process of both acceptance and coping with the challenges of care of their children.

\subsubsection{Financial Support from Church Groups}

The sixth strategy was receiving financial support from church groups. One father said: "I make sure she receives help and look for funds from family members (younger brother), friends and church groups to cater for her needs like toiletries. I tried to make her look presentable just like my other children." Clearly, religious convictions encouraged church members to provide financial resources to impaired children. This indicates that they felt duty-bound to relieve the challenges faced by families with impaired children.

It appears that when parents and guardians did not find assistance elsewhere, the church was always there to provide financial support. Accordingly, spiritual support remained a vital factor in assisting them to manage their children.

It is suggested that ways should be found to establish community based projects in horticulture in order to guarantee the availability of fresh produce and funds from sales.

\subsubsection{Material Support from a Pastor}

The seventh strategy was that of receiving material support from a pastor. One parent (mother) said: "Our pastor loves us so much. He always visits us, prays for my son's health and gives some groceries. The whole process is comforting. He is assisting us a lot spiritually and materially." These findings are in line with the findings by Poston and Turnbull (2004) who reported that spiritual support, congregational support, prayer and benevolent religious reframing were found to be helpful.

This perspective was further given weight by the same researchers who categorized religious coping strategies in order to determine which type of religious coping is helpful or harmful. It follows that the social nature of a religious community provides positive benefits to families with an impaired child and this includes material support from church members.

It appears that it remains the obligation of other religious members to provide food and clothes as charity to the impaired children. Perhaps the focus could be on religious responsibility intended to achieve spiritual recognition by God. Since people often turn to religion, it is suggested that religious institutions and pastors should be trained to provide pastoral counselling to parents and guardians of the impaired child.

\section{CONCLusion}

The objective of this study was to investigate coping strategies in families with intellectually impaired children at Dagbreek and Môreson Centres in the Khomas Education Region of Namibia. The findings revealed that parents and guardians received support in the form of: support from partners and siblings; support from the extended families; social support from others; professional support as well as spiritual support. It is further evident from the above findings that parents and guardians are stressed because of the burden of care they carry in raising their children. The researchers recommend that government and non-governmental organizations should intervene in order to assist parents and guardians to care for their children. Focus should be placed on support in the form of financial, spiritual and professional services from medical doctors, therapists and counsellors. Further research should be conducted on the support and care being provided for children suffering from intellectual impairment.

\section{REFERENCES}

[1] Abbeduto, L. Seltzer, M. M., Shattuck, P., Krauss, M.W., Orsmond, G., \& Murphy, M.M. (2004). Psychological well-being and coping in mothers of youths with autism, Down Syndrome, or Fragile X Syndrome. American Journal on Mental Retardation, 109, 237-254.

[2] Barnett, D., Clements, M., Kaplan-Estrin, M., \& Fialka, J. (2003). Building new dreams supporting parents' adaptation to their child with special needs. Infants and young children. 16(3):184-200. 
[3] Bauman, S. (2004). Parents of children with mental retardation: Coping Mechanisms and Support Needs. Unpublished Doctor of Philosophy Dissertation. USA: University of Maryland

[4] Cunningham, C. (1996). Families of Children with Down syndrome. Down syndrome Research and Practice. 4 (3), 87-95.

[5] Gay, L.R., Mills, G.E., \& Airasian, P. (2009). Educational Research: Competencies for Analysis and Application. New Jersey: Pearson Education.

[6] Glidden, L.M., Billings, F.J. \& Jobe, B.M. (2006). Personality, coping style and well-being of parents rearing children with developmental disabilities. Journal of Intellectual Disability Research. 50, 949-962.

[7] Gorman, G. E., Clayton, P. (2005). Qualitative research for the information professional: A practical handbook. London: Facet Publishing.

[8] Gupta, A. \& Singhal, N. (2004). Positive Perceptions of children with disabilities. Asia Pacific Disability Rehabilitation Journal, 15, (1), 22-35.

[9] Heller, T., \& Caldwell, J. (2006). Supporting aging caregivers and adults with developmental disabilities in future planning. Mental Retardation, 44,189- 202.

[10] Johnson, B. \& Christensen, L. (2008). Education Research; Quantitative, Qualitative and Mixed Approaches. $\left(2^{\text {nd }}\right.$ ed) New York: Pearson Education.

[11] Jones, J. \& Passey, J. (2003). Family Adaptation, Coping and Resources: Parents of Children with Developmental Disabilities and Behaviour Problems. Journal on Development Disabilities, $11,1$.

[12] Maulik, P.K., Mascarenhas, M.N., Mathers, C.D., Dua, T. \& Saxena, S. (2011). Prevalence of intellectual disability: A meta-analysis of population-based studies. Research in Developmental Disabilities, 32, 419-436.

[13] McCubbin, H. I. \& Patterson, J.M. (1983a \& 1983b). The family stress process: the Double ABCX Model of adjustment and adaptation. In Social Stress and Family: Advances and Developments in Family Stress Theory and Research (Eds H.I. McCubbin, M.B. Sussman and J. M. Patterson), pp.7- 37. New York: Haworth Press.

[14] Ministry of Basic Education and Culture (1999). Education Statistics. Windhoek: Education Management Information Systems.

[15] Morya, M., Agrawal. A, Upadhyaya, S. K. \& Sharma, D.K. (2015). Stress and coping strategies in families of mentally retarded children. Journal of Evolution of Medical and Dental Sciences, 4, 8977-8985.

[16] Neely-Barnes, S. L. \& Dia, D, A. (2008). Families of children with disabilities: a review of literature and recommendations for interventions. The Journal of Early and Intensive Behavioural Intervention, 18, 348 - 357.

[17] Oelofsen, N. \& Richardson, P. (2006). Sense of coherence and parenting stress in mothers and fathers of preschool children with developmental disability. Journal of Intellectual \& Developmental Disability, 31, 1-12.

[18] Plant, K. M., \& Sanders, M.R. (2007). Care-giver stress in families of preschool- aged children with developmental disabilities. Journal of Intellectual Disability Research, 51, 109-124.

[19] Poston, D. J. \& Turnbull, A.P. (2004). Role of spirituality and religion in family quality of life for families of children with disabilities. Education and Training in Developmental Disabilities, 39, 95-108.

[20] Seligman, M. \& Darling, R.B. (2007). Ordinary Families Special Children: A SystemsApproach to Childhood Disability. New York: The Guilford Press.

[21] Stoneman, Z. \& Gavidia-Payne, S. (2006). Marital adjustment in families of young children with disabilities: associations with daily hassles and problem- focused coping. American Journal on Mental Retardation, 111, 1-14.

[22] Swenson, S. (2005). Families, Research, and Systems Change. Mental Retardation, 43, 365-368.

[23] Turnbull, A.P., Turnbull, H.R., Erwin, E.J. \& Soodak, L.C. (2006). Families, Professionals, and Exceptionality ( $5^{\text {th }}$ ed.). Upper Saddle River, NJ: Pearson/ Merrill-Prentice Hall. 
[24] Venkatesan, S. (2003). Caregivers as teachers for kids with developmental disabilities (Cats for kidds): Abridged project report. All India institute of speech and hearing, Mysore. India.

[25] Ylven, R., Bjorck-Akesson, E. \& Granlund, M. (2006). Literature review of positive functioning in families with children with a disability. Journal of Policy and Practice in Intellectual Disabilities, 3, $253-270$.

\section{AUTHORS' BIOGRAPHY}

Ms Aina Simson, is a teacher at Pionier Boys' School in the Khomas region of Namibia. She holds a Master's Degree in Education with a specialization in Inclusive Education which she obtained from the University of Namibia, Namibia. She teaches in the area of learner support at primary level. She also works as part-time tutor- marker for distance students in the field of Early Childhood Development and as a mentor in a programme called "Community Based Work with Children and Youth at risk" (Psychosocial Support) at Namibia College of Open Learning. She further works as a tutor-marker Inclusive Education at the University of Namibia.

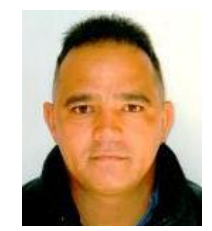

Prof. A.D. Möwes, is a Namibian with over 23 years of experience in teaching. He has been involved in the training of teacher's for the past 20 years. Prof. Möwes is an Associate Professor in the Department of Educational Psychology and Inclusive Education at the University of Namibia, Namibia. His research interests are predominantly in the areas of Inclusive Education, Guidance and Counselling, Intellectual Impairment and Advanced Research Methodology. He has been involved in the supervision of a number of Postgraduate students who have completed their studies successfully. $\mathrm{He}$ has served internal and external examiner for Master's students and Doctoral students at various African Universities. He also served as reviewer for a number of accredited journals in the region. 